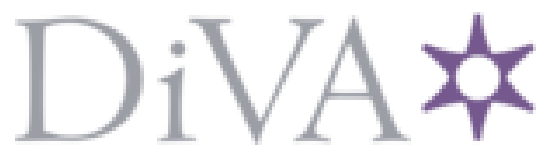

http://www.diva-portal.org

This is the published version of a paper presented at SPIE Optics + Photonics.

Citation for the original published paper:

van Stam, J., Van fraeyenhoven, P., Andersén, M., Moons, E. (2016)

Comparing Morphology in Dip-Coated and Spin-Coated Polyfluorene:Fullerene Films.

In: Zakya H. .Kafafi, Paul A. Lane, Ifor D.W. Samuel (ed.), Proc. of SPIE: Organic

Photovoltaics XVII (pp. 99420D-1-99420D-10).

https://doi.org/10.1117/12.2237819

N.B. When citing this work, cite the original published paper.

Permanent link to this version:

http://urn.kb.se/resolve?urn=urn:nbn:se:kau:diva-46358 


\title{
Comparing Morphology in Dip-Coated and Spin-Coated Polyfluorene:Fullerene Films
}

\author{
Jan van Stam*a, Paulien Van fraeyenhoven ${ }^{\mathrm{a}, \mathrm{b}}$, Mikael Andersén ${ }^{\mathrm{a}}$, Ellen Moons ${ }^{\mathrm{c}}$ \\ ${ }^{a}$ Physical Chemistry, Department of Engineering and Chemical Sciences, Karlstad University, \\ Karlstad, Sweden; \\ ${ }^{\mathrm{b}} \mathrm{UC}$ Leuven-Limburg, Leuven, Belgium; \\ ${ }^{c}$ Materials Physics, Department of Engineering and Physics, Karlstad University, Karlstad, Sweden
}

\begin{abstract}
When preparing the active layer film for organic optoelectronic devices, e.g., solar cells, spin-coating is often used for the deposition of the solution of electron donor and acceptor molecules. An alternative, among others, is to use dipcoating, where the substrate is dipped into the solution and subsequently withdrawn, all at coordinated speeds and times. In order to develop knowledge on how the final active layer morphology is influenced by preparation parameters, different coating methods are compared.

In this contribution, we report on a comparative study of thin deposited films from a model system. The investigated model system is poly (9,9-dioctylfluorene) (F8, also referred to as PFO) as donor and [6,6]-phenyl- $\mathrm{C}_{61}$-butyric acid methyl ester $\left(\mathrm{PC}_{60} \mathrm{BM}\right)$ as acceptor.

Combining fluorescence and absorption spectroscopy with atomic force microscopy allows us to conclude that dipcoating offers increased possibilities to manipulate the film morphology, that the transition of the glassy F8 $\alpha$-phase to the more ordered $\beta$-phase is influenced by the dipping speed as well as by the blend ratio, and that the long-wavelength emission of F8 cannot stem from the oxidized keto-F8 only.
\end{abstract}

Keywords: Organic photovoltaics; Fluorescence; UV/VIS absorption; Polymer blend; Film morphology; Deposition methods; Dip-coating

\section{INTRODUCTION}

The active layer of a polymer solar cell typically consists of a thin film of a conjugated polymer, acting as the electron donor, blended with a fullerene derivative, acting as the electron acceptor. This blend film has an internal nanostructure, referred to as the morphology, which is one of the decisive factors for the solar cell performance. ${ }^{1,2}$ If one wants to manipulate the morphology on a molecular level, it is necessary to understand the factors that determine the structure. ${ }^{1,3-7}$

Commonly, the active layer is prepared by spinning a thin film of the polymer and the fullerene derivative from solution upon a substrate under controlled conditions. This works quite well on a small scale, but is not suitable for large-area applications. An alternative, among others, is to use dip-coating, ${ }^{8,9}$ where the substrate is dipped into the solution of donor and acceptor and withdrawn, all at coordinated speed and time. Knowledge on how different coating methods influence the active layer morphology can be achieved by comparing different film deposition methods. Several forces are responsible for the formation of the film. ${ }^{10,11}$ Some of the most important parameters in dip-coating are the viscous drag, the gravitational force, and the capillary force. The viscous drag causes the liquid to go upward with the substrate when the substrate is withdrawn. This force is proportional to the liquid viscosity and the withdrawal speed. Gravity causes the solution to move downwards. The faster the substrate is withdrawn, the thicker the film will be.

We have recently shown that fluorescence and UV/VIS absorption spectroscopy are valuable tools for the study of polymer solar cell active layers, especially in combination with AFM measurements. Emphasis has been on the characterization of changes in film morphology and their influence on the electron transfer processes from donor to acceptor. ${ }^{12,13}$ In this contribution, we compare films prepared from chloroform solutions by two different preparation methods; the "standard" spin-coating method and the more versatile dip-coating method. The comparison has been

*Jan.van.Stam@kau.se; phone +46-547002479; www.kau.se

Organic Photovoltaics XVII, edited by Zakya H. Kafafi, Paul A. Lane, Ifor D. W. Samuel,

Proc. of SPIE Vol. 9942, 99420D - @ 2016 SPIE · CCC code: 0277-786X/16/\$18

doi: $10.1117 / 12.2237819$

Proc. of SPIE Vol. 9942 99420D-1 
performed on a model system, relevant for morphology studies of polymer/fullerene solar cells. The investigated model system is poly(9,9-dioctylfluorene) (F8) as donor and [6,6]-phenyl- $\mathrm{C}_{61}$-butyric acid methyl ester $\left(\mathrm{PC}_{60} \mathrm{BM}\right)$ as acceptor. ${ }^{14,15}$ The molecular structures of $\mathrm{F} 8$ and $\mathrm{PC}_{60} \mathrm{BM}$ are shown in Figure 1. Typically, the component with the lesser solubility in the chosen solvent will induce the phase separation and form a phase rich in that component, while the other phase will be rich in the component with better solubility. ${ }^{16,17}$ It should be stressed that the phase separation is partial, as the fast solvent evaporation prevents equilibrium conditions, and the resulting thin film active layer is in a non-equilibrium state. Our aim is to further develop the preparation methods and the understanding of the underlying processes yielding the film morphologies upon drying.
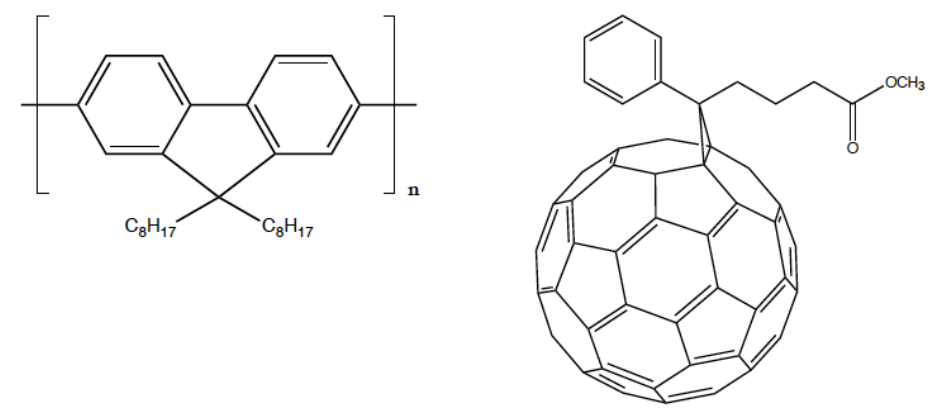

Figure 1. The donor polymer F8, (poly(9,9-dioctylfluorenyl-2,7-diyl)) (left), and the acceptor fullerene derivative $\mathrm{PC}_{60} \mathrm{BM}$ ([6,6]- phenyl- $\mathrm{C}_{61}$-butyric acid methyl ester) (right).

Steady-state fluorescence spectroscopy was used to study the emission of F8, in order to characterize the contribution of two different solid phases of the donor polymer. These phases, the $\alpha$-phase or the glassy state and the $\beta$-phase, which has a more coplanar and zigzag ordered structure, show clear differences in their emission spectra. The $\alpha$-phase has its emission maximum around 410 and $420 \mathrm{~nm}$ and shows no vibronic fine structure, while the emission from the $\beta$-phase is located between 440 and $500 \mathrm{~nm}$ and shows vibronic peaks. ${ }^{18,19}$ The mechanism of the formation of the $\beta$-phase structure is poorly understood, but it has been found in both films and in solution. ${ }^{20,21}$ There is also a third contribution to the emission spectra, a broad emission between 500 and $550 \mathrm{~nm}$. This emission is attributed to either a charge transfer state of F8 or to photo-oxidized F8 keto-states. ${ }^{18-25}$ Finally, UV/VIS absorption spectroscopy was used to quantify the presence of the $\alpha$ - and $\beta$-phases by a method proposed by Cone et al. ${ }^{24}$

\section{EXPERIMENTAL}

\section{Materials}

F8 (sometimes referred to as PFO), molecular weight 68000 (PS standard), was purchased from American Dye Source, Quebec, Canada. $\mathrm{PC}_{60} \mathrm{BM}$ (purity $>99 \%$ ) was purchased from Solenne, The Netherlands. Chloroform (CF), analytical grade, was purchased from Merck. All chemicals were used as received. Glass substrates for film deposition were from Menzer Gläser, Germany. The glass substrates were cleaned by detergent and thoroughly rinsed by distilled water and ethanol. After drying, the clean substrates were stored in CF prior to the film preparation.

\section{Sample preparation}

Spin-coating: Details on the preparation of the $\mathrm{F} 8: \mathrm{PC}_{60} \mathrm{BM}$ films by spin-coating is given by Björström et al. ${ }^{14}$ In short, blend solutions of $\mathrm{F} 8: \mathrm{PC}_{60} \mathrm{BM}$ of different weight/weight proportions, i.e., 2:1, 1:1, 1:2, 1:4, and pure $\mathrm{F} 8$ (1:0), were prepared in CF. The total materials concentration was $12.0 \mathrm{~g} / 1$. A small droplet of the solution was put onto the glass substrate and the substrate with droplet was spun at 1500 rpm during 80 seconds.

Dip-coating: Films were prepared by dip-coating using solutions with the same weight/weight proportions and solvent as for spin coating, but with lower concentrations; for this coating method the total materials concentration was $1.0 \mathrm{~g} / 1$. To 
achieve a constant dipping speed, a Newport Translation Stage UTS 100CC was used together with a Halcyonics MOD10 plus active vibration damping system.

The clean glass substrate was immersed into the solution and withdrawn at different speeds, i.e., 1, 5, 10, 20, and 40 $\mathrm{mm} / \mathrm{s}$. After evaporation of the solvent, a thin film of the products that were dissolved in the solvent is deposited on the substrate. The process is schematically shown in Figure 2. ${ }^{10}$
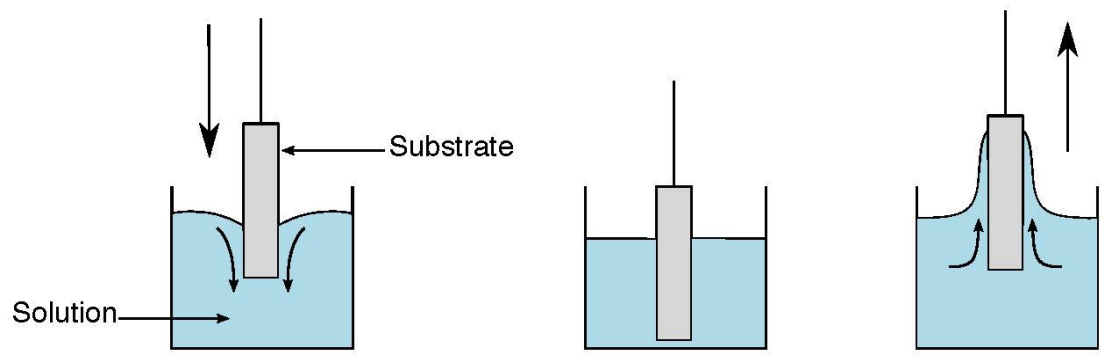

Figure 2. The principle of dip-coating.

\section{Atomic Force Microscopy}

The film topology was imaged by AFM measurements in tapping mode, performed on a DI Innova from Veeco Metrology using a Si tip.

\section{Steady-state fluorescence measurements}

The steady-state fluorescence spectra were measured on a Jobin-Yvon SPEX FL3-11 TAU fluorimeter, purchased from GammaData, Sweden. Measurements were performed in right-angle mode at $30^{\circ}$ angle, relative to the incident excitation light. The excitation wavelength was $\lambda_{\mathrm{ex}}=380 \mathrm{~nm}$ and the emission was recorded between $\lambda_{\mathrm{em}}=420-600 \mathrm{~nm}$. In order to prevent disturbance from scattered excitation light, a $400 \mathrm{~nm}$ longpass filter, with an optical density above 2, from Edmund Optics, was placed between the sample and the detector of the fluorimeter. All blend films were kept in the dark prior to the measurements and all spectra were recorded at room temperature.

\section{UV/VIS absorption measurements}

The UV/VIS absorption measurements were performed with a Cary $5000 \mathrm{UV} / \mathrm{VIS} / \mathrm{NIR}$ spectrophotometer, purchased from Agilent, Sweden. A clean glass substrate was used as reference. All spectra were recorded at room temperature.

\section{RESULTS AND DISCUSSION}

Films with different ratios between $\mathrm{F} 8$ and $\mathrm{PC}_{60} \mathrm{BM}$ and prepared by spin- and dip-coating were investigated with emphasis on the film nanostructure. AFM was employed to get images of the blend films, while spectroscopy methods yielded spectra used as "fingerprints" for the different structures present in the films.

\section{Film morphology from AFM}

Figure 3 shows the height images of spin- and dip-coated films. All films are strongly phase separated, yielding islands of one phase embedded in the other phase. The islands that are formed in the present system are rich in $\mathrm{PC}_{60} \mathrm{BM}^{14}{ }^{14}$ From morphology studies on spin-coated films, it is known that the size of the islands is depending on both the composition of the solution and the spin speed. ${ }^{10,16,17}$ As thicker films dry slower than thinner ones, one expects the islands to be larger when the film is thicker. i.e., slow drying will allow the phase separation to proceed further, yielding larger islands. 

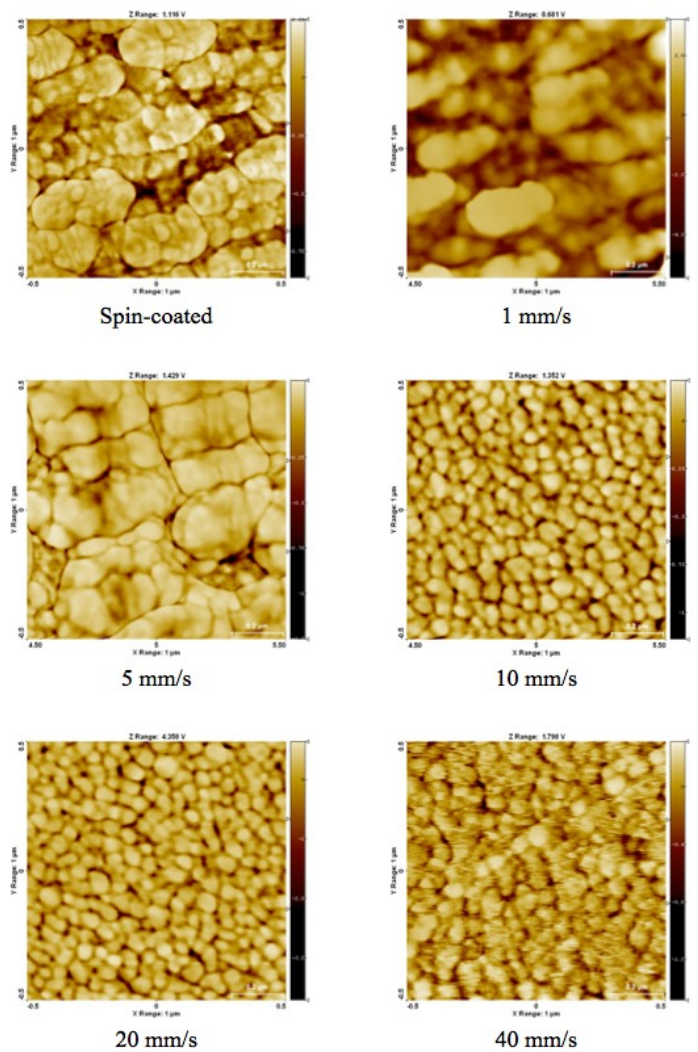

Figure 3: AFM height images for $\mathrm{F} 8: \mathrm{PC}_{60} \mathrm{BM}$ films with 1:1 ratio deposited by spin-coating and by dip-coating with different dipping speeds. Real size of each image is $1.0 \times 1.0 \mu \mathrm{m}$ and inserted bar is $0.2 \mu \mathrm{m}$.

The results from dip-coating show another picture. Even when the $\mathrm{F} 8: \mathrm{PC}_{60} \mathrm{BM}$ ratio is constant, a significant difference in the size of the islands can be noted for different dipping speeds, as is shown in Figure 3. The sizes of the islands for the spin-coated sample with $\mathrm{F} 8: \mathrm{PC}_{60} \mathrm{BM}$ ratio $1: 1$ and made with a dipping speed of $1 \mathrm{~mm} / \mathrm{s}$ and $5 \mathrm{~mm} / \mathrm{s}$ have islands that have a diameter of 200 to $300 \mathrm{~nm}$. When the dipping speed is $10 \mathrm{~mm} / \mathrm{s}, 20 \mathrm{~mm} / \mathrm{s}$, and $40 \mathrm{~mm} / \mathrm{s}$, the islands are noticeably smaller with diameters around $50 \mathrm{~nm}$.

Evidently, the faster the substrates were dipped, the smaller the islands became. This is contrary to what is anticipated considering that a faster withdrawal from the solution results in a thicker film, which would imply that the islands have more time to form and, hence, larger islands are expected. The AFM images show, instead, large islands for slow dipping speeds and significantly smaller islands for fast dipping speeds. This can be rationalised by the time-span that the substrate is located right above the solution. Chloroform, which was used as solvent, has a high vapour pressure and just above the solution there is a high concentration of solvent vapour. At low dipping speeds, the films will stay for a rather long time in an environment rich in evaporated solvent. This leads to what is known as solvent annealing, allowing the larger islands to form and, eventually, nucleation and crystal growth. This could be an explanation for a noticeable dissimilarity found; an abrupt difference in shape is detected going from $5 \mathrm{~mm} / \mathrm{s}$ to $10 \mathrm{~mm} / \mathrm{s}$. The same trend concerning the size of the islands versus the dipping speed is found for other $\mathrm{F} 8: \mathrm{PC}_{60} \mathrm{BM}$ ratios.

Turning to the blend composition, we find that the sizes of the islands differ at different ratios of $\mathrm{F} 8: \mathrm{PC}_{60} \mathrm{BM}$. The islands, which are rich in $\mathrm{PC}_{60} \mathrm{BM}$, become larger if the amount of $\mathrm{PC}_{60} \mathrm{BM}$ increases, at constant dipping speed, as expected. ${ }^{14}$ Figure 4 shows the AFM images for different ratios of $\mathrm{F} 8: \mathrm{PC}_{60} \mathrm{BM}$ when the films were prepared at a dipping speed of $10 \mathrm{~mm} / \mathrm{s}$. For the lowest amount of $\mathrm{PC}_{60} \mathrm{BM}$ in the film, the $2: 1$ ratio, the islands have a diameter of about 40 $\mathrm{nm}$. The islands in the 1:1 films have approximately the same diameter. When the ratio is changed to $1: 2$, the islands grow to a diameter of about $100 \mathrm{~nm}$. Finally, the film with the largest amount of $\mathrm{PC}_{60} \mathrm{BM}$, the 1:4 ratio, shows islands with diameters of $200 \mathrm{~nm}$. Further, the same dissimilarity in shape is found going from 1:1 to 1:2 as for the increasing dipping speeds, c.f. Figure 3. Films prepared at other dipping speeds show the same behaviour. 


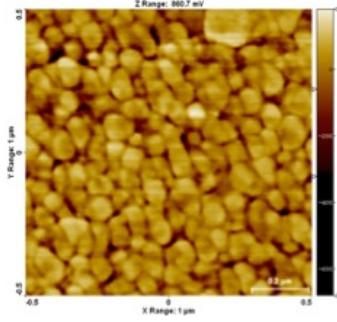

$2: 1$

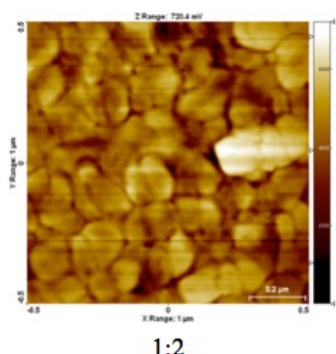

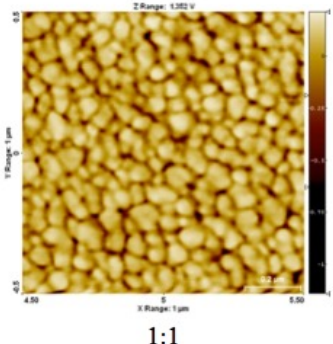

$1: 1$

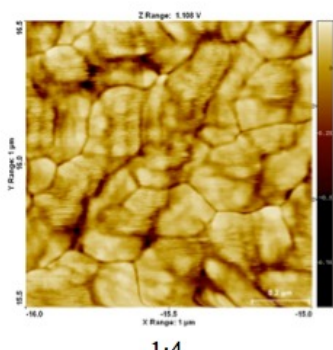

$1: 4$

Figure 4: AFM height images of F8: $\mathrm{PC}_{60} \mathrm{BM}$ films with different ratios that were dip-coated at $10 \mathrm{~mm} / \mathrm{s}$. Real size of each image is $1.0 \times 1.0 \mu \mathrm{m}$ and inserted bar is $0.2 \mu \mathrm{m}$.

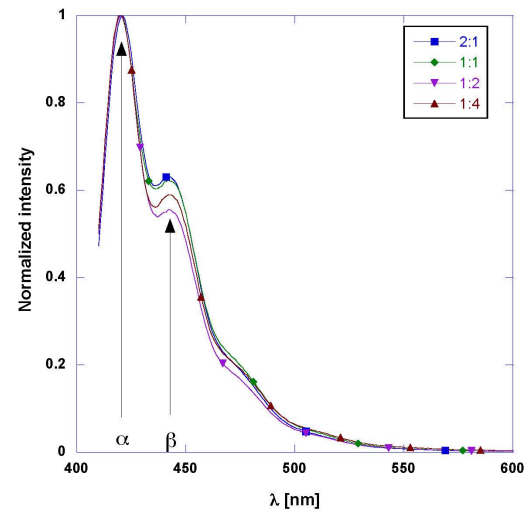

Figure 5. Fluorescence spectra of $\mathrm{F} 8: \mathrm{PC}_{60} \mathrm{BM}$ films prepared by spin-coating on glass substrates from chloroform solutions with different $\mathrm{F} 8: \mathrm{PC}_{60} \mathrm{BM}$ ratios, see legend. The excitation wavelength was $380 \mathrm{~nm}$. All spectra are normalized to their maximum fluorescence intensity. Inserted arrows indicate the approximate position of the emission peaks of the $\alpha$-phase and the $\beta$-phase.

\section{F8: $\mathrm{PC}_{60} \mathrm{BM}$ fluorescence in blend films}

The fluorescence spectra of the films as well as of the solutions (not shown), show three main emission regions: ${ }^{18,19}$ The F8 $\alpha$-phase emission between 410 and $420 \mathrm{~nm}$, the $\beta$-phase emission from located between 440 and $500 \mathrm{~nm}$, and a broad emission band between 500 to $550 \mathrm{~nm}$. There are two possibilities for this red-shifted emission: Either it originates from an intramolecular F8 charge transfer state or it stems from a photo-oxidized keto-state of F8. ${ }^{18-21}$ 
The emission spectra of the spin-coated $\mathrm{F} 8: \mathrm{PC}_{60} \mathrm{BM}$ films from chloroform, Figure 5, show a maximum peak from the F8 $\alpha$-phase. The fact that emission from the $\alpha$-phase is dominating the spectrum for all blend ratios can be ascribed to the short drying-time that the samples have when spin-coating is applied, hence not allowing the F8 chains to order themselves into a $\beta$-phase. There is a weak $\beta$-phase emission; it is most intense for the film with 2:1 composition, but almost independent of blend ratio. For the emission spectra from pure F8 film, spin-coated from CF (not shown), the intensities of the $\alpha$-phase and $\beta$-phase emissions are almost equal.

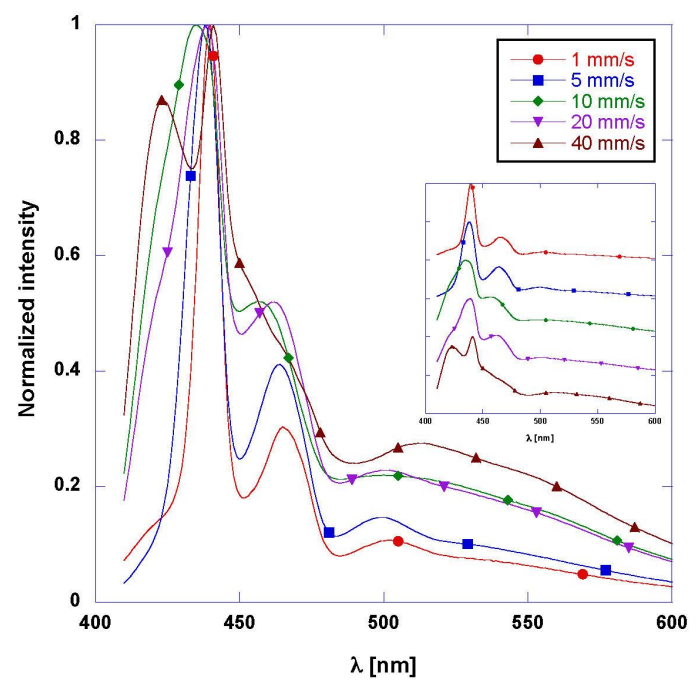

Figure 6. Fluorescence spectra of F8 films prepared by dip-coating on glass substrates from chloroform solutions with different dipping speeds, see legend. The excitation wavelength was $380 \mathrm{~nm}$. All spectra are normalized to their maximum fluorescence intensity. Inserted graph shows the shift of the maximum emission peak when changing the dipping speed.

In Figure 6, the emission spectra of $\mathrm{F} 8$ films, prepared by dip-coating from $\mathrm{CF}$, are shown. The emission maxima wavelengths for these films show a small dependence on dipping speed. The shape of the spectra, however, are strongly dependent on the dipping speed, see inserted graph in Figure 6. The $\beta$-phase is the most profound at lower speeds, i.e., thinner films, reflecting the influence of solvent annealing. During withdrawal, the time spent in the volume just above the solution, rich in solvent vapour, is long enough to yield a mobility of the molecules in the blend film and, hence, making it possible for F8 to transfer into the more ordered $\beta$-phase. Further, increasing the dipping speed yields a hypsochromic shift, due to an increasing amount of F8 in the glassy $\alpha$-phase. This becomes clear at the highest speed, i.e., $40 \mathrm{~mm} / \mathrm{s}$ (the thickest film), where the $\alpha$-phase peak is clearly separated from the $\beta$-phase emission. Most interestingly, the emission band between 500 and $550 \mathrm{~nm}$ also shows a clear dependence on the dipping speed. It is most intense at the highest dipping speed and decreases gradually with decreasing speeds. This result allows the conclusion that the broad emission band is not emanating from photo-oxidized keto-F8 only, as there is no reason to assume this photochemical process to be dependent on the dipping speed. Instead, we conclude that this emission originates, at least to a substantial amount in the studied system, from an intramolecular F8 charge transfer state, this state being dependent on the amount of $\alpha$-phase present and, hence, on the dipping speed. 
The spectra for the dip-coated films with $\mathrm{F} 8$ and $\mathrm{PC}_{60} \mathrm{BM}$ show that the peak wavelength is blue shifted when the dipping speed increases, in the same way as for pure F8 films. This is shown in Figure 7 for the 2:1 ratio and, again, the $\alpha$-phase and $\beta$-phase peaks are completely resolved at the highest dipping speed. The solvent annealing allows the polymer to set into the $\beta$-phase, which can be seen not only in the spectra for the $2: 1$ ratio, but for all ratios. An important observation is the complete lack of emission between 500 and $550 \mathrm{~nm}$, contrary to what was found for pure F8 films. This strengthens the assumption that this long-wavelength band is due to emission from a charge transfer state, as when $\mathrm{PC}_{60} \mathrm{BM}$ is added to $\mathrm{F} 8$, the charges are transferred to $\mathrm{PC}_{60} \mathrm{BM}$ and the emission between 500 and $550 \mathrm{~nm}$ disappears. The presence of $\mathrm{PC}_{60} \mathrm{BM}$ cannot cause the reduction of the keto-F8 to pure $\mathrm{F} 8$.

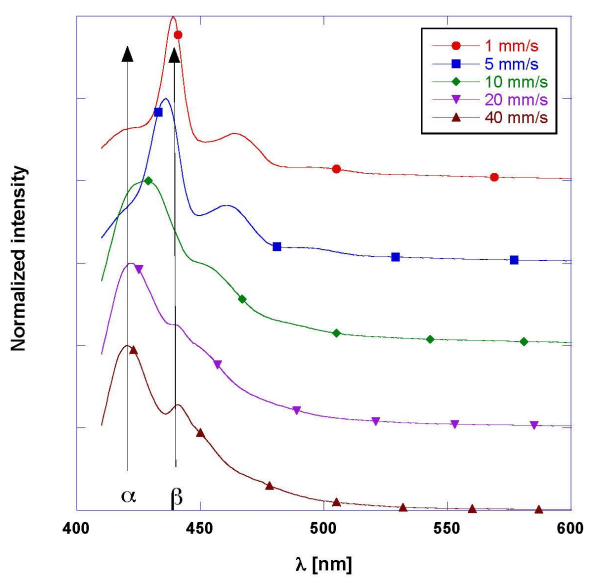

Figure 7. Fluorescence spectra of $\mathrm{F} 8: \mathrm{PC}_{60} \mathrm{BM}$ films (ratio 2:1) prepared by dip-coating on glass substrates from chloroform solutions with different dipping speeds, see legend. The excitation wavelength was $380 \mathrm{~nm}$. All spectra are normalized to their maximum fluorescence intensity. Inserted arrows indicate the approximate position of the emission peaks of the $\alpha$ phase and the $\beta$-phase.

\section{F8:PC ${ }_{60} \mathrm{BM}$ UV/VIS absorbance}

In the absorption spectra, two main regions can be found, emanating from the two different phases of F8. The $\alpha$-phase is found at wavelengths between 380 and $390 \mathrm{~nm}$ and for the $\beta$-phase this is around $440 \mathrm{~nm} .^{21,24}$

Figure 8 shows the spectra for $\mathrm{F} 8: \mathrm{PC}_{60} \mathrm{BM}$, with the ratio $2: 1$. The most intense absorption is from the $\alpha$-phase and the absorption from the $\beta$-phase shows a dependence on the dipping speed. The absorption spectra from spin- and dip-coated films are very similar, only differing in the absorption intensity from the $\beta$-phase. The amount of $\beta$-phase is clearly lower for the spin-coated films as compared to the dip-coated films with the same $\mathrm{F} 8: \mathrm{PC}_{60} \mathrm{BM}$ ratios. This is in line with the results from the fluorescence measurements and is due to the short time for the films to dry while spinning.

Cone et al. have proposed a method to get a qualitative value of the amount of $\beta$-phase in the films. Taking the ratio of the absorption at $440 \mathrm{~nm}$ to the absorption at $390 \mathrm{~nm}$ yields a value that can be used for comparison. The higher this value becomes, the more $\beta$-phase there is. ${ }^{24}$ The results of applying this method are given in Table 1 and graphically shown in Figure 9.

Table 1 shows very low values for the dip-coated and spin-coated pure F8 (1:0) films, values that are rather independent of coating speed. Hence, it can be concluded that very small amounts of $\beta$-phase are present in these films. The $\mathrm{F} 8: \mathrm{PC}_{60} \mathrm{BM}$ films from chloroform show significantly more $\beta$-phase than pure $\mathrm{F} 8$, and the amount of $\beta$-phase increases as the $\mathrm{PC}_{60} \mathrm{BM}$ weight fraction in the blend increases. This is especially pronounced at the lowest withdrawal speed for dip-coated films, i.e., the thinnest films. 


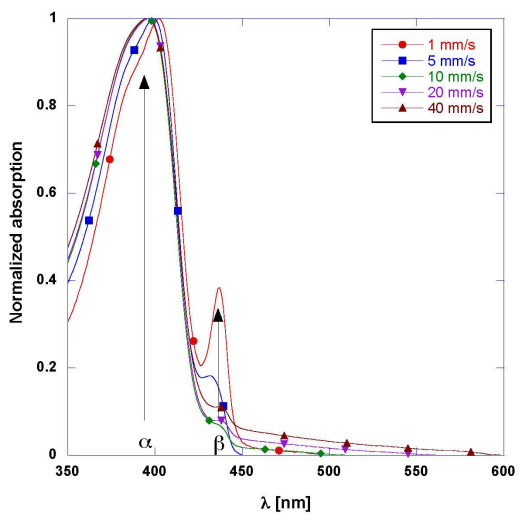

Figure 8. Absorption spectra of $\mathrm{F} 8: \mathrm{PC}_{60} \mathrm{BM}$ films (ratio 2:1) prepared by dip-coating on glass substrates from chloroform solutions with different dipping speeds, see legend. All spectra are normalized to their maximum absorption. Inserted arrows indicate the approximate position of the absorption peaks of the $\alpha$-phase and the $\beta$-phase.

Table 1: The relative amount of $\beta$-phase in the films with different amounts of $\mathrm{PC}_{60} \mathrm{BM}$, prepared by dip-coating at different dipping speeds and spin-coating from chloroform. The values are calculated from UV/VIS absorption data, with the model of Cone et al. ${ }^{24}$

\begin{tabular}{l|l|l|l|l}
\hline Composition & F8 (1:0) & $2: 1$ & $1: 2$ & $1: 4$ \\
\hline $1 \mathrm{~mm} / \mathrm{s}$ & 0 & 0.33 & 0.69 & 0.91 \\
$5 \mathrm{~mm} / \mathrm{s}$ & 0.06 & 0.10 & 0.34 & 0.73 \\
$10 \mathrm{~mm} / \mathrm{s}$ & 0.02 & 0.06 & 0.17 & 0.61 \\
$20 \mathrm{~mm} / \mathrm{s}$ & 0.06 & 0.07 & 0.18 & 0.54 \\
$40 \mathrm{~mm} / \mathrm{s}$ & 0.05 & 0.10 & 0.20 & 0.52 \\
\hline Spin coated & 0.01 & 0.06 & 0.23 & 0.28 \\
\hline
\end{tabular}

We observe a decreasing value for $\mathrm{A}_{440} / \mathrm{A}_{390}$ for increasing dipping speeds, Figure 9. As discussed earlier, a low dippingspeed allows for solvent annealing and hence also facilitates two coupled processes: $\mathrm{PC}_{60} \mathrm{BM}$ diffusion, on the one hand, and $\mathrm{F} 8$ aggregation into the $\beta$-phase, on the other hand. For $\mathrm{F} 8: \mathrm{PC}_{60} \mathrm{BM}$ blends with higher $\mathrm{PC}_{60} \mathrm{BM}$ fractions, the amount of $\beta$-phase also increases. This can be rationalised in terms of molecular interactions. Upon solvent annealing, the separation between the phases rich in $\mathrm{F} 8$ and rich in $\mathrm{PC}_{60} \mathrm{BM}$, respectively, continues and yields a better demixing of the blend film components. ${ }^{26}$ The more developed phase separation might lead to $\mathrm{PC}_{60} \mathrm{BM}$ nucleation, a process similar to what has been observed in other polyfluorene systems. ${ }^{27}$ If so, this could be a path to the interpretation of the AFM images in Figures 3 and 4, see discussion above. Further, a more developed phase separation and molecular mobility will also allow F8 to form the structured $\beta$-phase more easily. Following this hypothesis, the continued partial phase separation due to solvent annealing, influences the molecular ordering of the F8 polymer. 


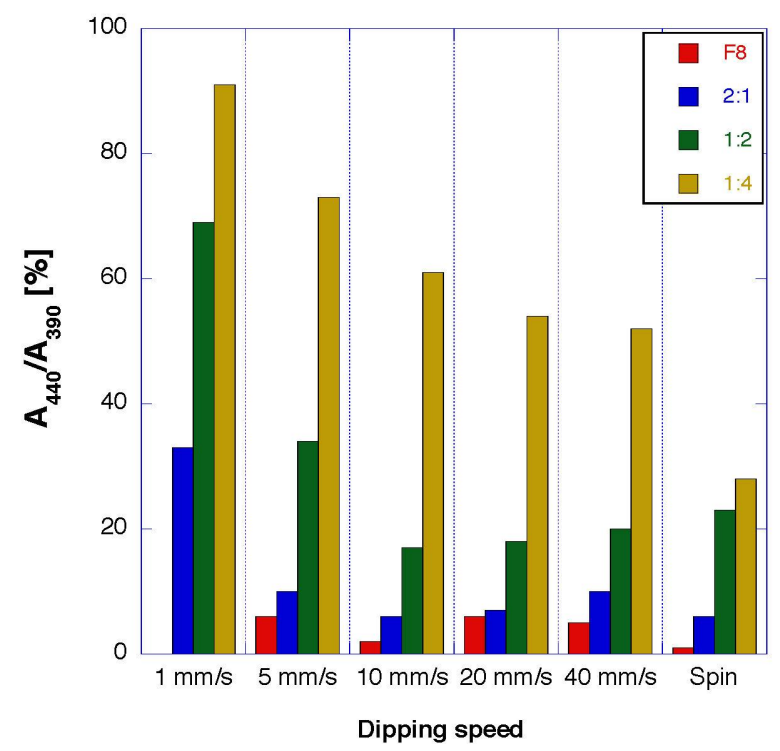

Figure 9. The relative amount of $\mathrm{F} 8 \beta$-phase for different $\mathrm{F} 8: \mathrm{PC}_{60} \mathrm{BM}$ ratios and preparation conditions. The calculations were performed according to the method proposed by Cone et al. ${ }^{24}$

\section{CONCLUSIONS}

The results show that similar morphological structures are obtained by the two preparation methods, and that the final film morphology can be manipulated by a proper choice of the dip-coating speed. This makes dip-coating more versatile, not only from an applied point of view, but also for fundamental research.

The main conclusions from the combination of AFM, fluorescence spectroscopy and absorption spectroscopy are, first, the formation of the ordered $\mathrm{F} 8 \beta$-phase from the disordered $\alpha$-phase depends both on the $\mathrm{F} 8: \mathrm{PC}_{60} \mathrm{BM}$ ratio and on the dipping speed, second, that the morphology can be tuned by both the composition of the solution and the dipping-speed, and, third, that the bathochromic emission of F8 cannot stem from the keto-F8 only.

The results presented in this contribution open doors for future research. Extending the comparison to films prepared from different solvents, solvents with different polarities and vapour pressures, will yield a deeper understanding of the effect of solvent annealing and molecular interactions during the drying process.

\section{ACKNOWLEDGEMENTS}

J.v.S. acknowledges the funding from the Swedish National Space Board under contract 148/14 and 151/15. E.M. acknowledges financial support from the Swedish Energy Council (Contract 38327-1), the Swedish Research Council (2015-03778), and from the Göran Gustafsson Foundation for Research in Natural Sciences and Medicine. P.V.f. was a visiting student at Karlstad University during the spring 2016, under the Erasmus ${ }^{+}$programme of the European Union. 


\section{REFERENCES}

[1] Peet, J. H., Heeger, A. J., and Bazan, G. C., Acc. Chem. Res. 42, 1700-1708 (2009).

[2] Salleo, A., Kline, R. J., DeLongchamp, D. M., and Chabinyc, M. L., Adv. Mater. 22, 3812-3838 (2010).

[3] Shaheen, S. E., Brabec, C. J., Sariciftci, N. S., Padinger, F., Fromherz, T., and Hummelen, J. C., Appl. Phys. Lett. 78, 841-843 (2001).

[4] Zhang, F., Jespersen, K. G., Björström, C., Svensson, M., Andersson, M. R., Sundström, V., Magnusson, K., Moons, E., Yartsev, A., and Inganäs, O., Adv. Funct. Mater. 16, 667-674 (2006).

[5] Yao, Y., Hou, J., Xu, Z., Li, G., and Yang, Y., Adv. Funct. Mater. 18, 1783-1789 (2008).

[6] Rispens, M. T., Meetsma, A., Rittberger, R., Brabec, C. J., Sariciftci, N. S., and Hummelen, J. C., Chem. Commun. 2116-2118 (2003).

[7] Arias, A. C., J. Macromol. Sci., C: Polymer Rev. 46, 103-125 (2006).

[8] Hu, Z., Zhang, J., Xiong, S., and Zhao, Y., Solar Energy Mater. Solar Cells 99, 221-225 (2012).

[9] Grosso, D., J. Mater. Chem. 21, 17033-17038 (2011).

[10] Yimsiri, P. and Mackley, M. R., Chem. Eng. Sci. 61, 3496-3505 (2006).

[11] Scriven, L. E., Mat. Res. Soc. Symp. Proc. Vol. 121, 717-729 (1988).

[12] van Stam, J., Hansson, R., Lindqvist, C., Ericsson, L., and Moons, E., Colloids. Surf. A: Physicochem. Eng. Aspects 483, 292-296 (2015).

[13] van Stam, J., Lindqvist, C., Hansson, R., Ericsson, L., and Moons, E., Proc. SPIE Vol. 9549, 95490L (2015).

[14] Björström, C. M., Magnusson, K. O., and Moons, E., Synth. Metals 152, 109-112 (2005).

[15] Beaupré, S., Boudreault, P.-L. T., and Leclerc, M., Adv. Mater., 22, E6-E27 (2010).

[16] Sprenger, M., Walheim, S., Budkowski, A., and Steiner, U., Interface Sci., 11, 225-235 (2003).

[17] Hansson, R., Ericsson, L. K. E., Holmes, N. P., Rysz, J., Opitz, A., Campoy-Quiles, M., Wang, E., Barr, M. G., Kilcoyne, A. L. D., Zhou, X., Dastoor, P., and Moons E., J. Mater. Chem. A 3, 6970-6979 (2015).

[18] Morgado, J., Alcácer, L., and Charas, A., Appl. Phys. Lett. 90201110 (2007).

[19] Tsoi, W. C., Charas, A., Cadby, A. J., Khalil, G., Adawi, A. M., Iraqi, A., Hunt, B., Morgado, J., and Lidzey, D. G., Adv. Funct. Mater. 18, 600-606 (2008).

[20] Tapia, M. J., Monteserín, M., Burrows, H. D., Deixas de Melo, J. S., Pina, J., Castro, R. A. E., García, S., and Estelrich, J., J. Phys. Chem. B 115, 5794-5800 (2011).

[21] Dias, F. B., Morgado, J., Maçanita, A. L. da Costa, F. P., Burrows, H. D., and Monkman, A. P., Macromolecules 39, 5854-5864 (2006).

[22] Gong, X., Iyer, P. K., Moses, D., Bazan, G. C., Heeger, A. J., and Xiao, S. S., Adv. Funct. Mater. 13, 325-330 (2003).

[23] Hintschich, S. I., Rothe, C., Sinha, S., Monkman, A. P., Scandiucci de Freitas, P., and Scherf, U., J. Chem. Phys. 119, 12017-12022 (2003).

[24] Cone, C. W., Cheng, R. R., Makarov, D. E., and Vanden Bout, D. A., J. Phys. Chem. B 115, 12380-12385 (2011).

[25] Lin, Z.-Q., Shi, N.-E., Li, Y.-B., Qiu, D., Lin, J.-L., Zhao, J.-F., Wang, C., Xie, L.-H., and Huang, W., J. Phys. Chem C 115, 4418-4424 (2011).

[26] Morgado, J., Moons, E., Friend, R. H., and Cacialli, F., Adv. Mater., 13, 810-814 (2001).

[27] McNeill, C. R., Watts, B., Thomsen, L., Belcher, W. J., Greenham, N. C., Dastoor, P. C., and Ade, H., Macromolecules 42, 3347-3352 (2009). 